\title{
Southern Ocean climate clues
}

\author{
Stephen Rintoul and an international team of oceanographers headed south on the Australian \\ icebreaker, Aurora Australis, to discover how Southern Ocean currents influence climate \\ and biodiversity.
}

What was the objective of the work? In the summer of 2007-2008 we sailed from Tasmania to Antarctica as part of a multinational effort to obtain a snapshot of the physical and biogeochemical state of the Southern Ocean during the International Polar Year. The main goal was to determine how the Southern Ocean is changing, and what this means for the future climate.

\section{Why did you choose this location?}

Exchange between the surface ocean and the deep sea largely determines how much heat and carbon dioxide can be stored by the oceans, and therefore the rate of climate change. In fact, more heat and carbon has accumulated in the Southern Ocean in recent decades than in any other latitude band on Earth. The region south of Tasmania is particularly interesting: it is one of the few places around Antarctica where dense water is formed and sinks to the deep ocean, and a long record of previous measurements exists so we can detect changes.

What sorts of data were you after? We used instruments lowered from the ship to measure temperature, salinity and oxygen concentrations. Water samples were collected from various depths and analysed for nutrients, carbon dioxide, chlorofluorocarbons, phytoplankton pigments and oxygen isotopes. We measured currents with acoustic instruments and deployed moorings to collect year-long records of water velocity and properties. Finally, the biodiversity team used nets, underwater cameras and corers to sample biota near the sea floor.

\section{Did you encounter any difficulties?}

The Southern Ocean is a tough workplace,

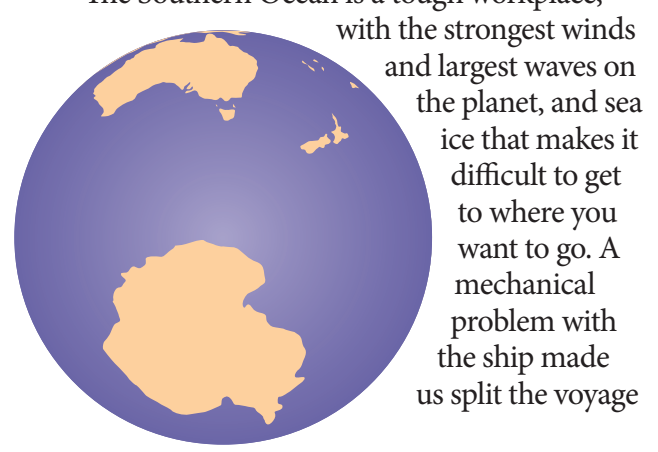

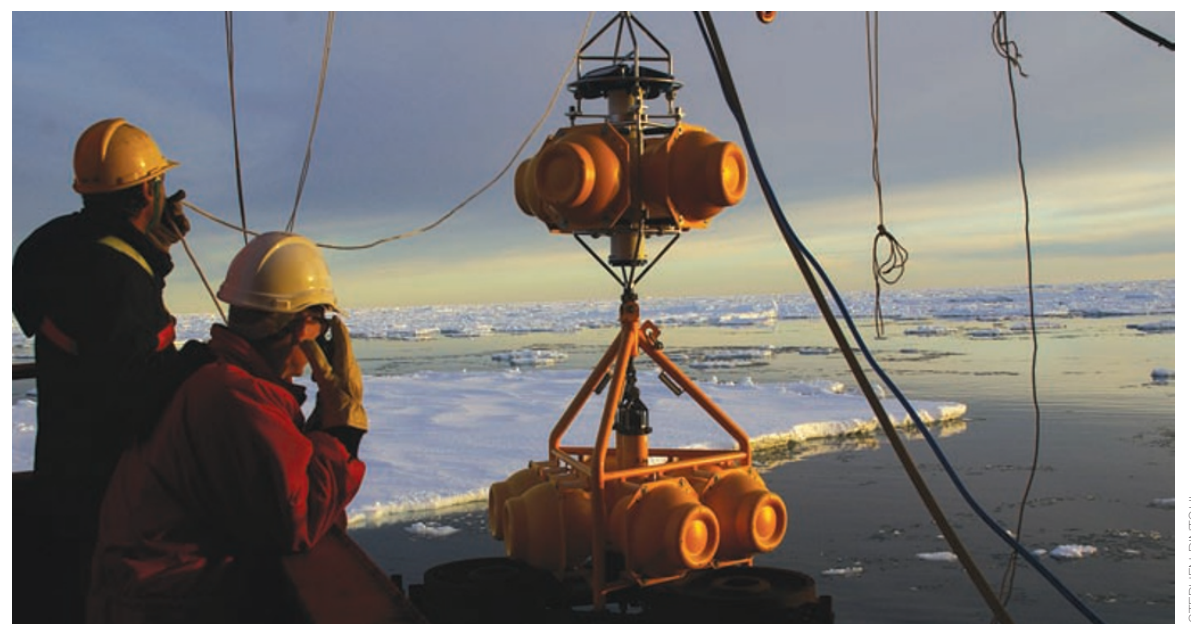

Deploying a mooring to measure the export of dense water from the Antarctic continental shelf.

into two trips, with the second part taking place late in the season when conditions are most likely to be challenging. As it turned out, we lost almost no time due to the weather.

Did you encounter dangerous animals? The closest we came to dangerous animals were some octopuses and fish with venomous spines (which were being studied by a team of venom experts on board).

Did you have any technical challenges? We needed to measure current directions on a mooring very close to the magnetic pole, where conventional compasses do not work. We decided to use a three-axis flux-gate compass that had been used for similar work in the Canadian Arctic region. We'll find out how well it worked when we pick up the moorings next summer.

What was the highlight of the expedition? Capturing a snapshot of the evolving state of the Southern Ocean as it responds to natural and anthropogenic-induced changes in climate forcing. We found that changes in high-latitude climate are being communicated rapidly to the deep ocean. Watching whales swim through a field of icebergs in the glow of the midnight Sun (while immersed in a jury-rigged hot tub heated with waste steam from the engine boiler) would have to rate pretty highly too.

Did the trip give you any ideas for future research projects?

We are just beginning to discover how and why the oceans are changing with time. Many questions remain: are the changes the result of human activity or natural variability? How do changes in the Southern Ocean influence the rest of the climate system? How sensitive is the ice sheet, and therefore sea level rise, to changes in ocean temperatures around the margin of Antarctica? To answer these questions we need sustained observations of the Southern Ocean using all the tools at our disposal (ships, satellites, floats, moorings and sensors mounted on animals).

\section{Any final thoughts?}

Although life at sea can have its difficult moments, it also brings a wider perspective on science and life, and a chance to make friends with people from different backgrounds. The communal sense of adventure and scientific stimulation is hard to reproduce on an autonomous float.

This is the backstory to the work by Stephen Rintoul and colleagues, published on page 864 of this issue. 